\title{
Gênero nos currículos dos cursos de licenciatura e bacharelado em Educação Física nas universidades de Minas Gerais
}

\section{RESUMO}

Neste trabalho, o objetivo principal foi analisar se as propostas curriculares dos cursos de licenciatura e bacharelado em Educação Física (EF) das universidades públicas do estado de Minas Gerais trabalham as questões de gênero em suas ementas. Utilizando as fontes documentais, em um estudo quantitativo e qualitativo, buscamos pelo descritor "gênero" nas ementas e nos nomes das disciplinas. Nossos resultados demonstraram uma carência da temática nos currículos e uma falta sobre o tema nas disciplinas direcionadas ao esporte. Um achado positivo foi $o$ fato das disciplinas de lazer discutirem sobre gênero. Concluímos que seria interessante mais pesquisas como essa em outros territórios brasileiros para ampliarmos a visão da EF no cenário nacional. Apontamos também para a urgente demanda das questões de gênero na sociedade em busca de reduzir não só as opressões de gênero, mas também todas as demais que as cercam.

PALAVRAS-CHAVE: Gênero; Currículo; Educação física; Universidade pública

\section{Carla Chagas Ramalho}

Mestre em Educação (UFRJ)

Universidade Estadual de Montes Claros, Departamento de Educação Física e do

Desporto, Montes Claros, Brasil carlaramalho.ccr@gmail.com https://orcid.org/0000-0002-6263-2498

Juliana Valéria Souza Santos

Licencianda em Educação Física Universidade Estadual de Montes Claros, Departamento de Educação Física e do

Desporto, Montes Claros, Brasil julianavaleriamoc@yahoo.com.br https://orcid.org/0000-0003-4955-6766

Fernanda de Souza Cardoso Doutora em Ciências da Religião (PUC-SP) Universidade Estadual de Montes Claros, Departamento de Educação Física e do

Desporto, Montes Claros, Brasil nandascard@yahoo.com.br

https://orcid.org/0000-0002-6384-1021

Marina Graziele Mendes Pereira Licencianda em Educação Física Universidade Estadual de Montes Claros,

Departamento de Educação Física e do

Desporto, Montes Claros, Brasil marinagrazzi@hotmail.com https://orcid.org/0000-0003-3506-2431 
Gender in the curriculum of undergraduate and bachelor's degrees in Physical Education at the universities of Minas Gerais

\begin{abstract}
In this work, the main objective was to analyze if the curricular proposals of the delicenciatura and baccalaureate courses in Physical Education (PE) of the public universities of the state of

Minas Gerais work on gender issues in their menus. Using mental sources, in a quantitative and qualitative study, we looked for the descriptor "gender" in the menus and in the names of the disciplines. Our results demonstrated a lack of the theme in the curricula and a lack on the theme in the disciplines directed to the sport. A positive finding was the fact that leisure disciplines discussed gender. We concluded that it would be interesting more research like this in other Brazilian territories to expand the Physical Education warning in the national scenario. We also point to the urgent demand of gender issues in society in order to reduce not only gender oppression, but also all the others that surround them.
\end{abstract}

KEYWORDS: Gender; Curriculum; Physical education; Public university

Género en los currículos de los cursos de licenciatura y bachillerato en Educación Física en las universidades de Minas Gerais

\title{
RESUMEN
}

En este trabajo, el objetivo principal fue analizar si las propuestas curriculares de los cursos delicenciatura y bachillerato en Educación Física (EF) de las universidades públicas del estado de Minas Gerais trabajan las cuestiones de género en sus menús. Utilizando las fuentes documentales, en un estudio cuantitativo y cualitativo, buscamos por el descriptor "género" en los menús y en los nombres de las disciplinas. Nuestros resultados demostraron una carencia de la temática en los currículos y una falta sobre el tema en las disciplinas dirigidas al deporte. Un hallazgo positivo fue el hecho de que las disciplinas de ocio discuten sobre género. Concluimos que sería interesante más investigaciones como esa en otros territorios brasileños para ampliar la visión de la Educación Física en el escenario nacional. Apuntamos también para la urgente demanda de las cuestiones de género en la sociedad en busca de reducir no solo las opresiones de género, sino también todas las demás que las rodean.

PALABRAS-CLAVE: Género; Currículo; Educación física; Universidad pública 


\section{INTRODUÇÃO}

O currículo é parte integrante exclusiva do ambiente escolar. É por meio dele que as normatizações do que deve ocorrer dentro das instituições de ensino são definidas, sendo assim, uma normatização no sentido de conteúdo e de normas sociais (YOUNG, 2014). Um entrelaçar de conhecimentos que servem para uma sociedade específica, buscando preparar cidadãos e cidadãs para o mundo e suas relações.

Com a compreensão dessa função do currículo, esta pesquisa se direcionou para as Instituições de Ensino Superior (IES), analisando as suas normatizações através dos conteúdos que determinadas instituições consideram importantes para futuros(as) professores(as) de Educação Física (EF), uma profissão que tem por essência o corpo e sua prática cultural. Assim, enxergamos como o entrelaçar das normatizações já citadas por Young (2014) são palpáveis nessa formação. Nosso foco foi o gênero como a arena social, compreendendo que esse retrata uma relação de poderes e hierarquizações sociais (CONNELL; PEARSE, 2015; CONNELL, 2016).

Temos duas categorias a serem investigadas nesse trabalho: currículo e gênero. Logo, nosso objetivo central nessa pesquisa é analisar se as propostas curriculares dos cursos de licenciatura e bacharelado em EF das universidades públicas do estado de Minas Gerais trabalham as questões de gênero em suas ementas. Nosso problema de pesquisa foi reconhecer como as IES de EF tem trabalhado com o tema sobre gênero em seus currículos. Levando em consideração a relação do tema com a construção social e seu impacto inquestionável, essa temática deve, ou deveria, ter a devida importância em tais documentos.

Utilizamos como metodologia as fontes documentais, pois elas trazem dados necessários para uma pesquisa quantitativa e qualitativa (GIL, 2008). Essa metodologia nos auxiliou a esquematizar a realidade do currículo das IES, verificando a estrutura curricular e as ementas das disciplinas estabelecidas nos cursos de licenciatura e bacharelado em EF das IES sediadas no estado de Minas Gerais. A documentação que foi analisada está disponível nos endereços eletrônicos das IES pesquisadas, proporcionando assim fontes documentais que permitiram uma dimensão quantitativa, sendo um facilitador para nossa pesquisa.

Para definição do universo do estudo, as IES públicas que possuem o curso de EF são: Universidade do Estado de Minas Gerais (UEMG), Universidade Federal de Minas Gerais(UFMG); Universidade Estadual de Montes Claros (UNIMONTES), Universidade Federal de Ouro Preto (UFOP), Universidade Federal de Viçosa (UFV), Universidade Federal de Uberlândia (UFU), Universidade Federal de São João Del Rei (UFSJ), Universidade Federal de Juiz de Fora (UFJF), Universidade Federal de Lavras (UFLA), Universidade Federal de Alfenas (UFA), Universidade 
Federal dos Vales do Jequitinhonha e Mucuri (UFVJM),Universidade Federal do Triângulo Mineiro (UFTM), Faculdade de Ciências da Saúde Archimedes Theodoro. Dessas universidades, nos debruçamos nas que ofereciam as duas habilitações em EF, isso fez com que fossem retiradas desse conjunto a ser analisado as seguintes instituições: Universidade Federal do Triângulo Mineiro (UFTM), Faculdade de Ciências da Saúde Archimedes Theodoro e Universidade Federal de Alfenas (UFA). A apreciação das propostas curriculares, das respectivas matrizes e ementas, foi feita por meio da análise de conteúdos (GOMES, 2002), buscando fazer uma pré-análise do material, em seguida explorá-lo, tratar os resultados e interpretá-los. Para auxiliar na nossa interpretação dos dados, dividimos a discussão em categorias,nomeadas como: O currículo; Perspectiva crítica de Gênero; e Gênero e EF.

\section{O CURRÍCULO}

Nesse trabalho, utilizaremos a corrente crítica do currículo para buscarmos associar a sua importância para as IES. Dessa forma, o currículo tem como significado de origem um espaço de conteúdo que determina o que os professores e professoras devem ensinar e o que os alunos e alunas devem aprender, dentro de uma sequência lógica. Porém, não podemos desconsiderar o embate e disputas de forças que englobam esse processo, tampouco minorar o papel pedagógico das(os) docentes e/ou desconsiderar que são cidadãos e cidadãs reais que fazem parte desse processo (SACRISTÁN, 2013).

Para Saviani (2007) o currículo da educação elementar é voltado para as exigências da vida em sociedade. No ensino médio, há uma relação explícita entre educação e trabalho, buscando a interação entre conhecimento e prática laboral. Na educação superior, o foco do ensino está relacionado em trazer para os(as) seus(suas) estudantes a possibilidade de participação integral na vida cultural da sociedade, ou seja, por meio dessa etapa educacional se diferencia os trabalhadores(as) "comuns” dos(as) de nível superior.

Assim, além do ensino superior destinado a formar profissionais de nível universitário (a imensa gama de profissionais liberais e de cientistas e tecnólogos de diferentes matizes), formula-se a exigência da organização da cultura superior com o objetivo de possibilitar a toda a população a difusão e discussão dos grandes problemas que afetam o homem contemporâneo. Terminada a formação comum propiciada pela educação básica, os jovens têm diante de si dois caminhos: a vinculação permanente ao processo produtivo, por meio da ocupação profissional, ou a especialização universitária (SAVIANI, 2007, p. 35).

Os currículos pressupõem uma normatização para uma sociedade almejada. Ao analisarmos um currículo, devemos ler como a formação de futuros(as) cidadãos(ãs) está sendo construída e como 
a classe dominante se respalda para se manter no poder, naturalizando atos e fatos no decorrer da vida acadêmica de todas as pessoas que passam por uma instituição escolar (YOUNG, 2014). Ao averiguarmos os currículos, faz-se importante remetermos essa construção a várias mãos e a uma disputa política na elaboração do mesmo. Ou seja, o currículo não é neutro.

Para a criação do currículo de cada IES, há um direcionamento através das Diretrizes Curriculares Nacionais. Diferentes instituições podem possuir matrizes curriculares distintas uma da outra para o mesmo curso de formação, porém é necessária a consonância com essas diretrizes nacionais.

Nossa Lei de Diretrizes e Bases da Educação Nacional deixa claro em seu artigo 53 que há autonomia das IES para: "fixar os currículos dos seus cursos e programas, observadas as diretrizes gerais pertinentes" (BRASIL, 1996). É crucial, porém, não negligenciarmos que essa autonomia passa por um processo evidente de disputa de forças por meio dos saberes que devem ser aplicados ou não.

\section{PERSPECTIVA CRÍTICA DE GÊNERO}

Quando falamos em gênero, precisamos saber que, obrigatoriamente, estamos trazendo raízes sociais para o debate. Não podemos falar sobre gênero, sendo a perspectiva que for, sem relacionar padrões sociais. Há imposição da sociedade pelo agir de determinada forma, cortar o cabelo de outra, calçar determinados sapatos, falar de determinada maneira, dentre inúmeras outras questões, porém, todas elas dependem do contexto social em que nos encontramos.

Considerando que a base econômica capitalista vigente molda a vida social, temos deforma palpável a compreensão que definições sociais e o capitalismo são inseparáveis (FONTES, 2014). As relações assimétricas direcionadas às classes sociais, essenciais para a existência do capitalismo, se coadunam de forma ímpar com a superioridade masculina exaltada pelo senso comum; sendo as mulheres vistas como sexo frágil, como propriedade, como naturalmente direcionadas para o cuidado e pela obrigatoriedade do trabalho não remunerado no seio dos lares (CISNE, 2018).

O gênero é um campo de expressões de forças que auxilia a determinar exploradas(os) e exploradores(as), uma arena que envolve poder e determina as relações e subrelações (CONNELL; PEARSE, 2015). Não é somente o capitalismo e esta arena reprodutora que embasam as relações humanas. Também não é possível vê-los de modo separado nem analítico dentro da realidade social. Como Saffioti (2004) já nos alertava, a interseção entre gênero, classe e raça precisa ser vista como um nó frouxo, que traz possibilidades flexíveis e variáveis para manter uma relação desequilibrada, na qual haverá sempre uma hierarquização de grupos. 
Foge da nossa pretensão explicar todas as questões relacionadas ao nó que Saffioti (2004) brilhantemente fala em sua obra. Mas, nos sentimos na obrigação de debruçarmos sobre essa proposta da autora para nos ajudar a entender que o sexismo, o racismo, o machismo e outras discriminações são parte de um mesmo contexto em que o foco é manter a ordem capitalista. Uma relação tão intrínseca que nenhuma se sobressai a outra e nem simplesmente se somam, como Saffioti (2004, p. 115) nos aponta: "não se trata de somar racismo + gênero + classe social, mas de perceber a realidade compósita e nova que resulta dessa fusão."

Ocorre um emaranhado de ligações que buscam reforçar e naturalizar opressões, seja por meio do racismo, da homofobia, do machismo ou de qualquer outra ação que cumpra o papel de manter a pirâmide social, com poucas pessoas no topo, sendo sustentadas pela base larga, que detém a maioria da população.

Essa explanação busca mostrar como a análise das questões de sexo e gênero não são demandas aleatórias ou individuais. Quando falamos de gênero, falamos obrigatoriamente de uma essência relacional com debates de exploração que jamais poderiam ser tratados de forma isolada, pois se fossem, não sobreviveriam em si. A exploração trazida pelo sexismo remete a um universo que não pode ser descontextualizado ou menosprezado. Para critérios acadêmicos e investigativos, o foco em um arranjo se faz pertinente, porém não devemos esquecer que é somente para uma análise didática e que não devemos pensar a realidade social de forma tão esterilizada e possível de pureza na sua essência. Lembremos que todos os arranjos fazem parte de uma mesma arena de disputa guiada pelos ideais de exploração que sustentam o capitalismo.

Assim, mediante a uma visão crítica da exploração de gênero, buscaremos interpretaras normatizações descritas dos currículos nas IES analisadas.

\section{GÊNERO E EDUCAÇÃO FÍSICA}

Todo corpo traz marcas, limites e possibilidades. Todo corpo social se molda e é moldado de acordo com expectativas e demandas específicas. Nesse sentido (trazendo uma interseção entre corpo, corpo social e gênero) falaremos como a EF possui uma contribuição no processo de manutenção ou, pode vir a ter, para a alteração da ordem capitalista. Por este motivo, como nos traz Soares et al. (1992), os(as) educadores(as) devem ter consciência de qual projeto social querem enaltecer em suas aulas, durante seus ensinamentos e nas trocas com os(as) estudantes.

Quando a base capitalista é fomentada durante as aulas de EF, há o reforço a naturalização da coisificação de pessoas por meio da sua cultura corporal. Historicamente, a EF em seu enredo faz apologia aos ideais capitalistas, apoiando-se 
[...] nos fundamentos sociológicos, filosóficos, antropológicos, psicológicos, e,enfaticamente, nos biológicos para educar o homem forte, ágil, apto, empreendedor,que disputa uma situação social privilegiada na sociedade competitiva de livre concorrência: a capitalista. Procura, através da educação, adaptar o homem à sociedade, alienando-o da sua condição de sujeito histórico, capaz de interferir na transformação da mesma (SOARES et al., 1992, p. 36).

Assim, a EF e sua história se interligam com um papel crucial dentro do ambiente escolar ou nos demais locais valorizando uma padronização e não a autonomia. Não coincidentemente, a EF conquistou seu espaço no ambiente escolar através da disciplinarização, de um discurso higienista e eugenista (MAGALHÃES, 2005), deixando profundas marcas para a formação na área, independente do seu campo de atuação. De maneira velada, muitas vezes mesmo sem ter tal percepção, a EF (através da prática de seus/suas docentes) também é responsável por um papel social que naturaliza padrões sociais, que separa, que fomenta a competição e tem um dizer que poderia ser slogan do capitalismo: "o importante é competir".

Importante relatar que a EF possui uma forte corrente crítica que confronta as demandas do capital de maneira direta, buscando a sua superação através da aplicação consciente da cultura corporal. Ou seja, a EF não é somente alienada e alienante, mas importante deixar claro como mesmo sendo tão desvalorizada, possui importância social particular por ser uma área de conhecimento que trabalha com a cultura corporal. Com essa EF crítica, temos lugar para enxergar o nó entre classe social, gênero e racismo durante as atividades da cultura corporal como intrínsecas.

Temos alguns trabalhos que trazem as relações entre gênero e a EF (ALTMANN, 2015; AUAD; CORSINO, 2017; GARCIA; BRITO, 2018), mas a maioria desses estudos são voltados para uma análise pós-estruturalista, com outro ideário conceitual. Precisamos deixar claro que essa visão de conceitos distintos não nos impede de reconhecer o quanto tais estudos ampliaram a discussão na área, possibilitando, inclusive, novas metodologias de ensino em busca de uma participação mais efetiva das pessoas menos habilidosas durante as aulas de EF.

Mesmo com a carência em trabalhos que discutam a EF e o gênero dentro dessa perspectiva crítica e anticapitalista, acreditamos, como demonstramos acima, que se trata de um terreno fértil para o debate de quem almeja uma sociedade justa e igualitária; compreendendo como a EF pode ser uma ferramenta importante para a justiça social que a perspectiva crítica almeja, interagindo com o nó (SAFFIOTTI, 2004) que trabalha, ao mesmo tempo, diferentes demandas do cotidiano e que acabam por reforçar a discriminação necessária para o sistema capitalista se manter.

Não há como falar em justiça social se não falarmos de respeito aos corpos, como também não podemos discorrer sobre trabalho justo quando há exploração do trabalho feminino, e ainda, não podemos nos pronunciar sobre liberdade, se existem limitações de ações para algumas e alguns. A 
integralidade das pessoas não deve ser corrompida, assim como o conhecimento e a realidade que a abarca. A EF pode vir a auxiliar esse entendimento por meio da expressão dos corpos, do reforço da liberdade de espaço e ações para todos(as) durante a sua prática, rompendo com predefinições destinadas a determinados gêneros, classes e raças.

\section{RESULTADO E DISCUSSÕES}

Neste tópico, vamos trazer o resultado da nossa busca. Analisamos um total de 1.234 ementas de oito IES. Não conseguimos apurar as ementas, conteúdos e objetivos de duas IES, sendo elas: Universidade Federal de Juiz de Fora e a Universidade Federal do Vale Jequitinhonha e Mucuri. Essas universidades não possuíam tais dados disponíveis em seus endereços eletrônicos, tendo à disposição apenas os nomes das disciplinas na matriz curricular. Ou seja, exclusivamente nessas IES, foram investigados os nomes das disciplinas (255 no total). Em cada busca, nos balizamos no descritor "gênero". Acreditamos que essa procura reflete se há uma demarcação curricular para o trato com a temática de gênero para trazer contribuições para a formação dos(as) discentes.

Por questões metodológicas, nosso recorte será direcionado ao gênero, sem focar na classe social e/ou raça durante a nossa pesquisa. Mas, como já abordamos em linhas anteriores, essa separação é apenas metodológica, por critérios científicos. Não podemos achar que apenas uma busca por palavras específicas dirá como o gênero é trabalhado nas universidades e nos cursos de EF. Ou seja, não ter essa palavra-chave nos documentos analisados não impossibilita de a temática ser trabalhada como objetivo ou especificamente como conteúdo dentro de uma disciplina trazida por algum(a) docente.

Importante salientar que fizemos buscas pela palavra gênero nas ementas das disciplinas e nos objetivos a serem alcançados ou ainda dentro dos conteúdos de cada disciplina.

Para facilitar a compreensão das leitoras e leitores, trouxemos os dados por tabelas, dividas pelas universidades pesquisadas, como podemos ver a seguir:

Tabela 1 - Nome da disciplina e onde se localiza a palavra "Gênero"

\begin{tabular}{|l|l|l|l|l|}
\hline Faculdade & Habilitação & Nome da disciplina e onde se localiza a palavra "Gênero" \\
\cline { 3 - 4 } & & Ementa & Objetivo & Conteúdo \\
\hline UEMG & Licenciatura & Educação Física e & - & - \\
& & Primeira Infância; & & \\
& & Educação Física, Jovens, & & \\
& & Adultos e Idosos; & & \\
& & Educação Física, & & \\
& & Segunda Infância e & & \\
& & Adolescência; & & \\
& & Futebol & & \\
\hline
\end{tabular}




\begin{tabular}{|c|c|c|c|c|}
\hline & Bacharelado & - & - & - \\
\hline \multirow[t]{2}{*}{ UFV } & Licenciatura & $\begin{array}{l}\text { Prática de Ensino II; } \\
\text { Prática de Ensino IV; } \\
\text { Corpo, Gênero, } \\
\text { Sexualidade e Educação } \\
\text { (optativa) }\end{array}$ & - & - \\
\hline & Bacharelado & - & - & $\begin{array}{l}\text { Estudo do Lazer I; } \\
\text { Ética, Bioética e Saúde } \\
\text { Pública }\end{array}$ \\
\hline \multirow[t]{2}{*}{ UFMG } & Licenciatura & $\begin{array}{l}\text { Direitos humanos; } \\
\text { Educação Física, Infância } \\
\text { e Juventude; } \\
\text { Educação Física e } \\
\text { Velhice; } \\
\text { Educação Física, Corpo e } \\
\text { Cultura }\end{array}$ & - & - \\
\hline & Bacharelado & $\begin{array}{l}\text { Educação física, Infância } \\
\text { e Juventude; } \\
\text { Educação Física e } \\
\text { Velhice }\end{array}$ & - & - \\
\hline \multirow[t]{2}{*}{ UNIMONTES } & Licenciatura & $\begin{array}{l}\text { Fundamentos da } \\
\text { Educação Física Escolar }\end{array}$ & - & - \\
\hline & Bacharelado & - & - & - \\
\hline \multirow[t]{2}{*}{ UFOP } & Licenciatura & - & - & - \\
\hline & Bacharelado & - & - & - \\
\hline \multirow[t]{2}{*}{ UFU } & Licenciatura & $\begin{array}{l}\text { Prointer II (Projetos } \\
\text { Interdisciplinares); } \\
\text { Fundamentos } \\
\text { Sociológicos da } \\
\text { Educação Física }\end{array}$ & - & $\begin{array}{l}\text { Educação Física Escolar e } \\
\text { Diferenças; } \\
\text { Psicologia da Educação. }\end{array}$ \\
\hline & Bacharelado & $\begin{array}{l}\text { Prática Pedagógica e } \\
\text { Diversidade Humana }\end{array}$ & - & $\begin{array}{l}\text { Estudos do lazer; } \\
\text { Sociologia do Esporte }\end{array}$ \\
\hline \multirow[t]{2}{*}{ UFSJ } & Licenciatura & Jogos e Brincadeiras & $\begin{array}{l}\text { Fundamentos Sócio- } \\
\text { Antropológicos aplicados } \\
\text { à Educação Física }\end{array}$ & - \\
\hline & Bacharelado & Jogos e Brincadeiras & $\begin{array}{l}\text { Fundamentos Sócio- } \\
\text { Antropológicos aplicados } \\
\text { à Educação Física }\end{array}$ & - \\
\hline \multirow[t]{2}{*}{ UFJF } & Licenciatura & - & - & - \\
\hline & Bacharelado & - & - & - \\
\hline
\end{tabular}




\begin{tabular}{|l|c|c|c|l|}
\hline UFLA & Licenciatura & Sociologia da Educação & - & $\begin{array}{l}\text { Aspectos Socioculturais } \\
\text { da Educação Física, } \\
\text { Esporte e Lazer (optativa) }\end{array}$ \\
\cline { 2 - 5 } & Bacharelado & $\begin{array}{l}\text { Sociologia da Educação } \\
\text { (eletiva) }\end{array}$ & - & $\begin{array}{l}\text { Aspectos Socioculturais } \\
\text { da Educação Física, } \\
\text { Esporte e Lazer (optativa) }\end{array}$ \\
\hline UFVJM & Licenciatura & - & - & - \\
\cline { 2 - 5 } & Bacharelado & - & - & - \\
\hline
\end{tabular}

Fonte: Elaboração própria

Os resultados apresentados na tabela representam a pesquisa das propostas curriculares das dez universidades públicas do estado de Minas Gerais. Ao analisar as ementas, os objetivos e conteúdos de cada disciplina foram encontradas, no total, trinta e uma disciplinas com a palavra "gênero". Localizamos um maior quantitativo na habilitação voltada para a licenciatura, de forma comparativa com o bacharelado.

Tabela 2 - Comparativo entre licenciatura e bacharelado

\begin{tabular}{|c|c|}
\hline Habilitação & Disciplinas com a palavra "Gênero" \\
\hline Licenciatura & 19 \\
\hline Bacharelado & 11 \\
\hline
\end{tabular}

Fonte: Elaboração própria

Achamos pertinente trazer o total de disciplinas de cada IES e relacionar com o total de disciplinas com a palavra gênero na sua ementa, conteúdo ou objetivo em sua habilitação (licenciatura ou bacharelado):

Tabela 3 - Comparativo quantitativo entre disciplinas obrigatórias de licenciatura e bacharelado e as que utilizam a palavra "gênero" na sua ementa, conteúdo ou objetivo

\begin{tabular}{|c|c|c|c|c|}
\hline IES & $\begin{array}{l}\text { Total de disciplinas } \\
\text { - LICENCIATURA }\end{array}$ & $\begin{array}{c}\text { Total de disciplinas } \\
\text { com a palavra gênero - } \\
\text { LICENCIATURA }\end{array}$ & $\begin{array}{l}\text { Total de disciplinas - } \\
\text { BACHARELADO }\end{array}$ & $\begin{array}{c}\text { Total de disciplinas com } \\
\text { a palavra gênero - } \\
\text { BACHARELADO }\end{array}$ \\
\hline UEMG & 53 & 4 & 57 & 0 \\
\hline UFV & 50 & 3 (sendo uma optativa) & 46 & 2 \\
\hline UFMG & 50 & 4 & 41 & 2 \\
\hline UNIMONTES & 58 & 1 & 51 & 0 \\
\hline UFOP & 55 & 0 & 55 & 0 \\
\hline UFU & 40 & 4 & 36 & 3 \\
\hline UFSJ & 51 & 2 & 52 & 2 \\
\hline UFJF & 75 & 0 & 72 & 0 \\
\hline UFLA & 59 & 2 (sendo uma optativa) & 57 & $\begin{array}{c}2 \text { (sendo uma optativa e } \\
\text { outra eletiva) }\end{array}$ \\
\hline UFVJM & 47 & 0 & 45 & 0 \\
\hline
\end{tabular}

Fonte: Elaboração própria 
Tabela 4 - Porcentagem de disciplinas obrigatórias que possuem a palavra "gênero" na sua ementa, conteúdo ou objetivo

\begin{tabular}{|c|c|c|}
\hline IES & Licenciatura & Bacharelado \\
\hline UEMG & $7,5 \%$ & $4,8 \%$ \\
\hline UFV & $4 \%$ & $4,3 \%$ \\
\hline UFMG & $8 \%$ & $4,8 \%$ \\
\hline UNIMONTES & $1,9 \%$ & $0 \%$ \\
\hline UFOP & $0 \%$ & $0 \%$ \\
\hline UFU & $10 \%$ & $8,3 \%$ \\
\hline UFSJ & $3,9 \%$ & $3,9 \%$ \\
\hline UFJF & $0 \%$ & $0 \%$ \\
\hline UFLA & $1,6 \%$ & $0 \%$ \\
\hline UFVJM & $0 \%$ & $0 \%$ \\
\hline
\end{tabular}

Fonte: Elaboração própria

Reforçamos na nossa análise que as ementas e as propostas curriculares dos cursos deformação são importantes para delimitar as funções sociais esperadas dos(as) formandos(as) em questão. Como Young (2014) nos alerta sobre a função normatizadora e social do currículo, temos uma visão de quais conteúdos serão ou não mais estimulados a serem trabalhados durante a prática pedagógica. Com base nessa importância, ter conteúdos que abordem temas relacionadas a gênero deve, ou deveria, ser incentivado por auxiliar na formação de futuras(os) professoras(es), seja dentro do ambiente escolar ou fora dele.

Para analisarmos de forma mais ordeira os dados encontrados na nossa pesquisa,fizemos uma divisão de categorias pós-determinadas (GIL, 2008), sendo elas: Disciplinas e gênero; Esporte e gênero; Disciplinas de lazer.

\section{DISCIPLINAS E GÊNERO}

Quando analisamos diretamente a palavra "gênero" nas ementas, contabilizamos apenas trinta e uma disciplinas que usam o termo, sendo vinte e uma vezes nas ementas. Dessas, três disciplinas são optativas, ou seja, os acadêmicos e as acadêmicas poderão escolher se irão cursá-las ou não. Com isso, alguns alunos e alunas que passarão por essa formação não terão contato com esse conhecimento, ao menos de forma normativa, regulada pelo currículo da instituição. Nas outras dez disciplinas, a temática gênero aparece como objetivo a ser alcançado ou conteúdo da disciplina.

Ao analisarmos o nosso resultado, reforçamos os dados de algumas pesquisas que nos antecederam. Trazemos como exemplo o estudo de Araújo e Silva (2019), ao avaliar o projeto político pedagógico da Escola de Educação Física e Desportos da Universidade Federal do Rio de Janeiro. Foi constatado, nesse trabalho, que a palavra gênero não aparece dentro do documento analisado. Apenas é citado o vocábulo "diversidade" duas vezes no campo "perfil do egresso", onde é colocado 
que deve ser uma competência do futuro professor ou professora saber adequar as atividades de acordo com a diversidade do público. Nicolino (2018 apud ARAÚJO; SILVA, 2019) também relata em seu estudo que a presença de discussões sobre gênero dentro dos currículos de EF em toda região do Brasil, remete-se à apenas $10 \%$ dos documentos.

Segundo Araújo e Devide (2019), em uma pesquisa feita com quatro universidades do Rio de Janeiro, foram encontradas apenas quatro disciplinas dentro da proposta curricular de três IES, que abordavam a temática de gênero ou sexualidade. Conforme os autores, essas disciplinas representam 0,85\% das ementas analisadas em um total de 467 ementas, destacando também que dessas quatro disciplinas, duas são optativas.

Transformando o nosso resultado total em porcentagem, temos os seguintes dados: apenas 2,51\% de disciplinas trazem a palavra "gênero" nas habilitações de EF nas universidades públicas do estado de Minas Gerais; uma redução se comparado ao estudo de Nicolino (2018 apud ARAÚJO; SILVA, 2019) e um aumento, se relacionado à pesquisa de Araújo e Devide (2019). Analisando particularmente as IES, $10 \%$ de disciplinas com a temática gênero, refletindo a maior porcentagem que achamos em uma universidade, especificamente na UFU. Nas demais IES, a porcentagem foi inferior, mostrando o quanto as instituições analisadas ainda estão aquém deste debate.

Mais do que relacionar quantitativamente esses dados, fazemos questão de trazer outras porcentagens que mostram a relevância dessa temática ser debatida em disciplinas de todos os cursos de graduação, assim como os cursos de EF, veja a seguir:

No ano de 2017, houve 12.112 registros de violência contra pessoas trans e 257.764casos de violência contra homossexuais ou bissexuais no Brasil. Foram 11 agressões contra pessoas trans e 214 contra pessoas homo/bi no país a cada dia. No mesmo ano, mulheres foram $67 \%$ das vítimas de agressão física registradas no país. No Distrito Federal, esse índice chegou a 75\% (GÊNERO E NÚMERO, 2020, s/p).

Como podemos perceber através dos números trazidos acima, referentes às violências de gênero no cenário nacional, há uma necessidade social para as IES se atentarem para esta demanda. Logo, acreditamos que o debate dentro de um curso de graduação que se embasa no corpo, na cultura corporal, no movimento, na ação histórica e social que o corpo nos proporciona, ajudará (sem ter a pretensão de uma solução simplista) o desatar de nós sociais que resultam numa violência descabida para quem está à margem dos padrões sociais.

Assim, durante a prática corporal da EF, em diferentes espaços, essa naturalização pode ser reforçada, incentivada ou questionada e problematizada. Um olhar atento do(a) professor(a), mediador(a) das atividades, para as questões de gênero se faz pertinente,afim de buscarmos um caminho para a redução de violências e discriminações relacionadas a essa temática. De tal modo, se 
não houver um alerta ao menos durante a graduação sobre essas questões, dificultar-se-á um olhar crítico e sensível desses(as) profissionais sobre essas problemáticas.

Sabemos que somente essa ação não colocará fim no sexismo de toda uma sociedade, mas compreendemos que qualquer passo em direção a uma experiência comunitária mais justa, nos ajuda a chegar ao respeito coletivo que incentivamos. Souza Júnior (2020), na atividade experimentada e intitulada "Futebol Generificado", cria regras e estipula condições específicas para iniciar o jogo, alterando as regras no decorrer da atividade e estimulando a participação de todas as pessoas, meninos, meninas, habilidosas(os), não habilidosas(os).

Enfim, nossas experiências com o Futebol Generificado têm evidenciado uma necessidade de se abrir o diálogo sobre temas correlatos às relações de gênero como forma inclusive de empoderamento de meninas e tomada de consciência de meninos sobre a urgência de rever atitudes e normas socialmente 'naturalizadas' e convencionadas que alimentam a lógica androcêntrica estabelecida (SOUZA JÚNIOR, 2020, p. 54).

Esse jogo, demonstrado pelo autor, deve servir apenas como incentivo para demais professores(as) verem a possibilidade real de trabalhar e debater de forma conjunta e coletiva com seus alunos e alunas. Não deve servir como manual para ser aplicado sem modificações em qualquer local, em qualquer tempo e sem a menor discussão sobre as ações. Acreditamos que a forma de incentivo para a igualdade de gênero parte de diferentes ações, mas a principal e imprescindível é o exemplo do convívio positivo no ambiente de aplicação de ensino (seja nas academias, escolinhas ou na educação básica), vindo daí o debate e problematizações quando se fizer necessário.

\section{ESPORTE E GÊNERO}

Outra análise que achamos pertinente compartilhar nesse estudo é relacionada aos conteúdos direcionados aos esportes, fazendo uma intercessão desses conhecimentos com as questões de gênero, pois julgamos ser necessária no contexto social. O esporte surge como conteúdo quase hegemônico da EF (ARAÚJO; ROCHA; BOSSLE, 2018) e possui uma função social e histórica muito pertinente, que, se não trabalhada de forma crítica, servirá parar e forçar opressões, oposições e grupo de vencidos(as) e de perdedores(as).

Por essa razão, o esporte deve ser visto além do seu gesto técnico e motor: "se aceitamos o esporte como fenômeno social, tema da cultura corporal, precisamos questionar suas normas, suas condições de adaptação à realidade social e cultural da comunidade que o pratica, cria e recria." (SOARES et al., 1992, p. 71). Ao ter uma intercessão com as demandas relacionadas sobre gênero, 
sexismo e feminismo, o esporte pode vir a se tornar um potente conteúdo para explanação de problematizações dentro da sociedade.

Por esse prisma, o cenário ideal para uma educação crítica e igualitária, seria debatermos sobre gênero dentro das disciplinas direcionadas para o ensino esportivo no curso de formação em EF. Porém, na nossa busca encontramos apenas em uma ementa essa relação entre esporte e gênero: Futebol - UEMG. O que demonstra como o esporte pode ser visto ainda de uma forma tradicionalista, enaltecendo inclusive papéis sociais de gênero específicos, sem uma problematização para os mesmos. Se tornando coeso com uma onda conservadora atual em nossa sociedade (SILVA; MACIEL; FRANÇA, 2020).

Essa relação intrínseca entre esporte e papéis sociais já fora trazida por algumas autoras(es). Para Connell e Pearse (2015) o esporte é uma expressão da masculinidade hegemônica que deve ser enaltecida na sociedade; servindo como modelo do que é ser homem viril, másculo, corajoso, potente, entre outras características de uma masculinidade que muitas vezes sufoca sensibilidades e dificulta a prática esportiva de uma forma ampliada e com problematizações pertinentes. Foca-se apenas em um padrão de gênero que deve ser seguido, e quem não o reproduz deve ser tolhido de tal prática, como as mulheres e os meninos que não se adéquam a tais posturas hegemônicas, ambos os grupos sofrendo discriminação do grupo proprietário do espaço e da força.

O processo esportivo exaltado auxilia a fundamentar a hierarquização de corpos, o que fomenta a naturalização da hierarquização de pessoas, de classes, de grupos. Esse processo é relacionado a dinâmicas pertinentes dos corpos na sociedade, que resultam em dinâmicas sociais e, por isso, são nomeadas de corporificação social (CONNELL, 2016). Ver com clareza esse processo reforça como o esporte, sendo conteúdo majoritário da EF, acaba por ser serviente a ideais capitalistas, se não tiver uma contextualização histórica na sua aplicação (SOARES et al., 1992).

Logo, se faz prioridade para uma atuação não alienada e nem alienante, termos uma visão ampla do esporte e sua atuação, assim como das opressões de gênero e sua magnitude que refletem em relações na/da sociedade. Promover, na formação profissional, debates obrigatórios sobre a exposição do corpo feminino nas práticas esportivas, por exemplo, pode nos auxiliar a desatar nós que direcionam a sociedade para uma arena reprodutiva ampla, que abarca diversos campos sociais. Mostra-se, dessa forma, como diferentes categorias de assédios servem para direcionar exercícios de poder sobre corpos e moldam realidades possíveis (CONNELL; PEARSE, 2015).

Não somos contra aplicação do conteúdo de esportes nas aulas de EF, mas acreditamos que trabalhá-lo de forma ampla e consciente é primordial para os(as) docentes que voltam a sua prática pedagógica para a classe trabalhadora e que tenham em mente uma sociedade justa e sem explorações de classe, raça ou de gênero. Por essa razão, os currículos dos cursos de EF, ainda mais de IES 
públicas, terem em sua constituição o esporte trabalhado de forma crítica, pode ser uma potente ferramenta de resistência e transformação social.

\section{DISCIPLINAS DE LAZER}

Se observarmos as disciplinas encontradas, vamos reparar que quase um terço das disciplinas do bacharelado que trabalham com o conteúdo sobre gênero, estão na área do lazer. Do total de onze disciplinas, três são direcionadas para o lazer, são elas: Estudos do Lazer I (UFV); Estudos do Lazer (UFU); Aspectos Socioculturais da EF, Esporte e Lazer(eletiva) (UFLA).

Para dimensionarmos a importância dos dados achados, primeiro iremos conceituar o lazer dentro da perspectiva crítica desse trabalho. Para isso, utilizamos a compreensão de que o lazer serve não só para demarcar atividades do tempo livre do proletariado, mas também para regularizar e normalizar ações sociais, criando sentidos e valores. Dessa forma, o lazer deve ser "[...] visto como um produtor de sociabilidade e não só como um fruto dessa” (SOUZA, 2011, p. 113).

Assim, relacionamos as naturalizações advindas dos momentos de lazer com as expressões de gênero que devem ser padronizadas no ambiente social. Se criamos e temos como natural o espaço público, as quadras nas aulas de EF, os bares como locais majoritariamente masculinos, precisamos enxergar a relação direta entre lazer, gênero e sexismo que abarca tal temática.

Leiro (2002, p. 10) reforça essa relação entre esses campos, como podemos ver:

Lazer e gênero se cruzam antes de entrar na escola ou no parque. Educação e gêneros e cruzam na educação familiar e podem, a qualquer tempo, reproduzir ou ressignificar estereótipos e valores. As visões de mundo se forjam gradativamente a partir de diferentes experiências pedagógicas - de culturas corporais, de vivências ambientais, de conhecimentos lógico-matemáticos e resultam de experiências oriundas da modalidade formal e não formal da educação. Inclusive dos livros didáticos que ainda hoje associam a mulher a tarefas domésticas como: cuidar das crianças e do lar. Tais visões ainda se reproduzem nas cenas do cotidiano como registra a epígrafe do subtítulo do presente artigo, quando traz a fala de uma mulher indignada com a divisão desigual da responsabilidade com o lazer das crianças e a consequente subtração do seu lazer (LEIRO, 2002, p. 10).

Por esse motivo, acreditamos que trabalhar com as desigualdades de gênero por meio da relação entre lazer e sociedade, se torna pertinente e propício por uma relação intrínseca que ambos os temas têm com a demanda para uma sociedade que não enalteça a hierarquização de pessoas. Devemos inquirir sobre a ocupação de corpos femininos e masculinos nos espaços públicos de lazer ou nos espaços privados, relacionar como a sociedade encara a necessidade e a premissa do lazer para as pessoas e de forma distinta para os gêneros. Compreender como diferentes gêneros leem o lazer e 
têm a possibilidade real de vivenciá-lo. Todas essas possibilidades trazem grande abertura para a desnaturalização social, já citada nesse trabalho, relacionada às questões de gênero.

Acreditamos que a habilitação no bacharelado em EF reflete um papel social ao atribuir debates sobre gênero nas suas disciplinas de lazer, se for visto com o intuito de problematizar tal realidade. Sobre as distintas habilitações no campo de EF, faz-se necessário esclarecer que ainda há um ferrenho debate sobre a formação acadêmica e as áreas de atuação para cada habilitação (RAMALHO; CARDOSO, 2021). Nesse trabalho segmentamos a área de atuação, por ser dessa forma que o curso se apresenta até o momento, porém consideramos que toda a prática da(o) formada(o) em EF é direcionada para uma atuação pedagógica. Compreendendo a prática pedagógica como uma ação de ensinar e aprender de forma mútua, dentro de uma progressão e dentro de uma relação entre pessoas.

Por mais que ainda exista uma separação normatizadora para os conteúdos das habilitações de licenciatura e bacharelado, entendemos as disciplinas que relacionam lazer e gênero como uma brecha para a atuação pedagógica, pertinente dessa formação. As IES que buscaram essa interação, a nosso ver, demonstram como lazer e gêneros se relacionam (LEIRO, 2002), mas também como lazer e educação se relacionam. Demonstrando uma preocupação com a prática pedagógica consciente desses(as) formandos(as).

Reforçamos que, em qualquer local de atuação, é mister compreender que a pessoa formada em EF, que aplica seu conhecimento através da cultura corporal, assume o papel de professor(a), de alguém que educa usando diferentes estratégias e recursos. Sendo, dessa maneira, fundamental esse entendimento para assumir a responsabilidade pedagógica que lhe cabe.

\section{CONSIDERAÇÕES FINAIS}

Ao finalizarmos essa pesquisa, julgamos que conseguimos alcançar o objetivo almejado, mapeando as matrizes curriculares das universidades públicas de Minas Gerais e sua intercessão com a temática sobre gênero. Concluímos que as normatizações curriculares desses cursos ainda estão aquém do idealizado para formação de profissionais críticos e conscientes na sua atuação profissional relacionada as questões de gêneros, principalmente de pessoas que têm a proximidade com a prática pedagógica e acultura corporal. Mostramos como há relações intrínsecas entre as demandas sociais, políticas e econômicas, ou seja, como se forma uma teia entre diversos campos da relação social que busca naturalizar explorações e opressões que são condizentes com uma sociedade capitalista. 
Com esse trabalho, esperamos auxiliar no debate sobre a temática, dando subsídios quantitativos e qualitativos para as IES sobre a importância dessa discussão e a atual carência da mesma. Buscamos mostrar como ainda temos um índice exacerbado de violência de gênero na sociedade e como docentes da área de EF podem vir a reforçar ou questionar essas violências; e também como acomodam a ideia de que alguns grupos devem sim ser superiores a outros. Corroboramos essa relação dentro da EF através, principalmente, da prática esportiva que retrata o embate entre um grupo e o outro, tendo como incentivo primário a competição.

A EF é uma ferramenta ímpar, dentro do contexto educacional, que pode vir a servir a corrente conservadora vigente ou para uma resistência que vise a emancipação da sociedade. Podemos observar como a temática sobre gênero é um assunto em disputa para acorrente conservadora ao analisarmos propagações de ideais como "ideologia de gênero" e "escola sem partido", que tentam inibir o papel problematizador e crítico da educação e da escola ao propor a manutenção de valores sem questionamentos.

Reforçamos que nenhum conteúdo deve ser deixado de lado na aplicação das aulas de EF, mas que todos eles devem ser vistos e requeridos com a devida responsabilidade pedagógica e social. Sugerimos que mais pesquisas como essas sejam feitas no cenário nacional para termos um parâmetro e uma relação de como a EF brasileira tem se posicionado perante as questões sociais tão urgentes e pertinentes. Torcemos para que o resultado encontrado na nossa pesquisa não represente a maioria dos estados e que a opressão de gênero, ou qualquer outra, tenha a sua devida atenção no cenário curricular.

\section{REFERÊNCIAS}

ALTMANN, Helena. Educação física escolar: relações de gênero em jogo. São Paulo: Cortez, 2015.

ARAÚJO, Ana Beatriz Carvalho de; DEVIDE, Fabiano Pries. "Gênero" e "sexualidade" na formação em educação física: uma análise dos cursos de licenciatura das instituições de ensino superior públicas do rio de janeiro. Arquivos em Movimento, Rio de Janeiro, v. 15, n. 1, p. 25-41, jan. 2019. Disponível em: https://revistas.ufrj.br/index.php/am/article/view/21840. Acesso em: 13 ago. 2021.

ARAÚJO, Gabriela Gomes; SILVA, Andréa Costa da. Gênero e sexualidade na licenciatura em educação física (EEFD/UFRJ): reflexões a partir do projeto político pedagógico. Temas em Educação Física Escolar, Rio de Janeiro, v. 4, n. 2, p. 36-59, ago. 2019. Disponível em:

https://www.cp2.g12.br/ojs/index.php/temasemedfisicaescolar/article/view/2244. Acesso em: 13 ago. 2021.

\footnotetext{
${ }^{1}$ Os termos usados correspondem as ideologias neoconservadoras que reforçam falácias sobre doutrinação de docentes aos seus alunos e alunas, como também um posicionamento neutro do ambiente escolar (o que já vimos ser impossível em tal ambiente).
} 
ARAÚJO, Samuel Nascimento de; ROCHA, Leandro Oliveira; BOSSLE, Fabiano. Sobre a monocultura esportiva no ensino da educação física na escola. Pensar A Prática, Goiânia, v. 21, n. 4, p. 824-835, out. 2018. Disponível em: https://www.revistas.ufg.br/fef/article/view/50175/pdf. Acesso em: 13 ago. 2021.

AUAD, Daniela; CORSINO, Luciano. O professor diante das relações de gênero na educação física escolar. São Paulo: Cortez, 2017.

BRASIL. Lei de Diretrizes e Bases da Educação Nacional. Lei no 9394, de 20 de dezembro de 1996. Estabelece as diretrizes e bases da educação nacional. Brasília, DF, 1996. Disponível em: http://www.planalto.gov.br/ccivil_03/leis/19394.htm. Acesso em: 13 ago. 2021.

CISNE, Mirla. Feminismo e marxismo: apontamentos teórico-políticos para o enfrentamento das desigualdades sociais. Serviço Social \& Sociedade, São Paulo, n. 132, p. 211-230, maio 2018. Disponível em: https://www.scielo.br/j/sssoc/a/kHzqt9vwyWmMyFd6hZjDmZK/?lang=pt\&format=pdf. Acesso em: 13 ago. 2021.

CONNELL, Raewy; PEARSE, Rebeca. Gênero: uma perspectiva global. São Paulo: nVersos, 2015.

CONNEL, Raewyn. Gênero em termos reais. São Paulo: nVersos, 2016.

FONTES, Virgínia. O Brasil e o capital-imperialismo. Teoria e História.Rio de Janeiro: EPSJV/Editora UFRJ, 2010.

GARCIA, Rafael Marques; BRITO, Leandro Teofilo de. Performatizações queer na educação física escolar. Movimento, Porto Alegre, v. 24, n. 4, p. 1321-1334, out. 2018. Disponível em: https://www.redalyc.org/jatsRepo/1153/115360468019/115360468019.pdf. Acesso em: 13 ago. 2021.

GIL, Antonio Carlos. Métodos e técnicas de pesquisa social. São Paulo: Atlas S.A, 2008. 6.ed.

GOMES, Romeu. A análise de dados em pesquisa qualitativa. In: MINAYO, Maria Cecília deSouza (Org.). Teoria método e criatividade. Petrópolis, RJ: Vozes, 2002. 21. ed. p. 75-76.

LEIRO, Augusto Cesar Rios. Educação, lazer e relações de gênero: talhes e doxas. Motrivivência, Florianópolis, n. 19, p. 1-16, 2002. Disponível em:

https://periodicos.ufsc.br/index.php/motrivivencia/article/download/956/4329/15695.

Acesso em: 13 ago. 2021.

MAGALHÃES, Carlos Henrique Ferreira. Breve histórico da educação física e suas tendências atuais a partir da identificação de algumas tendências de ideais e ideias de tendências. Revista da Educação Física, Maringá, v. 16, n. 1, p. 91-102, 2005. Disponível em: http://cev.org.br/biblioteca/breve-historico-educacaofisica-suas-tendenciasatuais- partir-identificacao-algumas-tendencias-ideais-ideias-tendencias/. Acesso em: 13 ago. 2021.

MORE: Mecanismo online para referências, versão 2.0. Florianópolis: UFSC Rexlab, 2013. Disponível em: http://www.more.ufsc.br/. Acesso em: 02 dez. 2021.

RAMALHO, Carla Chagas; CARDOSO, Fernanda de Souza. A adequação à exploração do mercado de trabalho via segmentação da Licenciatura e Bacharelado em Educação Física. Pensar A Prática, Goiânia, v. 24, p. 1-19, ago. 2021. Disponível em: https://www.revistas.ufg.br/fef/article/view/65902. Acesso em: 13 ago. 2021.

Redação gênero e número. Mapa da violência de gênero: mulheres são quase $67 \%$ das vítimas de agressão física no Brasil. Pub. 13 ago. 2021. Disponível em: http://www.generonumero.media/mapa-da-violencia-degenero-mulheres-sao-quase-67-dasvitimas-de-agressao-fisica-no-brasil/. Acesso em: 13 ago. 2021. 
SACRISTÁN, José Gimeno. Saberes e incertezas sobre o currículo. Porto Alegre: Penso, 2013.

SAVIANI, Dermeval. Trabalho e educação: fundamentos ontológicos e históricos. Revista Brasileira de Educação, São Paulo, v. 12, n. 34, p. 152-165, jan. 2007. Disponível em:

https://www.scielo.br/j/rbedu/a/wBnPGNkvstzMTLYkmXdrkWP/?lang=pt\&format=pdf. Acesso em: 13 ago. 2021.

SOUZA, Marianna de Alencar e. Marx e a produção do lazer na contemporaneidade. Revista Eletrônica de Ciências Sociais, Juiz de Fora, v. 5, n. 13, p. 106-119, set. 2011. Disponível em:

https://periodicos.ufjf.br/index.php/csonline/article/view/17233. Acesso em: 13 ago. 2021.

SAFFIOTI, Heleieth Iara Bongiovani. Gênero, patriarcado, violência. São Paulo: FundaçãoPerseu Abramo, 2004.

SILVA, Segislane Moésia Pereira da; FRANÇA, Marlene Helena de Oliveira; MACIEL, Valnise Verás. Conservadorismo como instrumento capitalista em tempos de barbárie. Revista Katálysis, [s. l], v. 23, n. 2, p. 256-265, maio 2020. Disponível em: https://periodicos.ufsc.br/index.php/katalysis/article/view/198202592020v23n2p256. Acesso em: 13 ago. 2021.

SOARES, Carmen Lúcia; TAFFAREL, Celi NelzaZulke; CASTELLANI FILHO, Lino;ESCOBAR, Michele Ortega; BRACHT, Valter. Metodologia do ensino de educação física. São Paulo: Cortez, 1992.

SOUZA JÚNIOR, Osmar Moreira. Gênero, educação física escolar e pedagogia do esporte: construindo processos educativos empoderadores. In: WENETZ, Ileana; ATHAYDE,Pedro; LARA, Larissa (Orgs.). Gênero e sexualidade no esporte e na educação física. Natal, RN: Ciências do esporte, educação física e produção do conhecimento em 40 anos de CBCE,2020. 6. ed. p. 47-51.

YOUNG, Michael. Teoria do Currículo: o que é e por que é importante. Cadernos de Pesquisa, São Paulo, v. 44, n. 151, p. 190-202, jan. 2014. Disponível em:

https://www.scielo.br/j/cp/a/4fCwLLQy4CkhWHNCmhVhYQd/?lang=pt. Acesso em: 13 ago. 2021.

\section{NOTAS DE AUTOR}

\section{AGRADECIMENTOS}

Aos/As avaliadores(as) do texto que colaboraram com a melhora do mesmo.

CONTRIBUIÇÃO DE AUTORIA

Concepção do manuscrito: C. C. Ramalho, F de S. Cardoso.

Coleta de dados: J. V. S. Santos, M. G. M. Pereira.

Análise de dados: C. C. Ramalho, J. V. S. Santos, F de S. Cardoso, M. G. M. Pereira.

Discussão dos resultados: C. C. Ramalho

Produção do texto: C. C. Ramalho, F de S. Cardoso.

Revisão e aprovação: C. C. Ramalho.

FINANCIAMENTO - Não se aplica.

CONSENTIMENTO DE USO DE IMAGEM - Não se aplica

APROVAÇÃO DE COMITÊ DE ÉTICA EM PESQUISA - Não se aplica.

CONFLITO DE INTERESSES - Não se aplica 


\section{LICENÇA DE USO}

Os autores cedem à Motrivivência - ISSN 2175-8042 os direitos exclusivos de primeira publicação, com o trabalho simultaneamente licenciado sob a Licença Creative Commons Attribution Non-Comercial ShareAlike (CC BY-NC SA) 4.0 International. Esta licença permite que terceiros remixem, adaptem e criem a partir do trabalho publicado, desde que para fins não comerciais, atribuindo o devido crédito de autoria e publicação inicial neste periódico desde que adotem a mesma licença, compartilhar igual. Os autores têm autorização para assumir contratos adicionais separadamente, para distribuição não exclusiva da versão do trabalho publicada neste periódico (ex.: publicar em repositório institucional, em site pessoal, publicar uma tradução, ou como capítulo de livro), com reconhecimento de autoria e publicação inicial neste periódico, desde que para fins não comerciais e compartilhar com a mesma licença.

\section{PUBLISHER}

Universidade Federal de Santa Catarina. Programa de Pós-Graduação em Educação Física. LaboMídia Laboratório e Observatório da Mídia Esportiva. Publicado no Portal de Periódicos UFSC. As ideias expressadas neste artigo são de responsabilidade de seus autores, não representando, necessariamente, a opinião dos editores ou da universidade.

\section{EDITORES}

Mauricio Roberto da Silva, Giovani De Lorenzi Pires, Rogério Santos Pereira.

EDITOR DE SEÇÃO

Silvan Menezes dos Santos

REVISÃO DO MANUSCRITO E METADADOS

Keli Barreto Santos; Juliana do Rosário.

\section{HISTÓRICO}

Recebido em: 09 setembro 2021

Aprovado em: 25 novembro 2021 